GOMES, A. R. A.; SOUZA, J. M. A.; LIMA, Y. M. M.; VIEIRA, M. S. T. C.; LIMA JÚNIOR, G. V.; ALENCAR, F. C. Produção de sabonetes artesanais a partir do óleo essencial do manjericão (Ocimum basilicum L.)

\title{
Produção de sabonetes artesanais a partir do óleo essencial do manjericão (Ocimum basilicum L.)
}

\author{
Handmade soaps production from basil (Ocimum basilicum L.) essential oil
}

\section{GOMES, Amanda Rosália Araújo. Graduanda em Licenciatura em Química.}

Instituto Federal do Sertão Pernambucano - Campus Petrolina. Rua Maria Luiza de Araújo Gomes Cabral, S/N, João de Deus - Petrolina - Pernambuco - Brasil. CEP: 56.316-686 / Telefone: (87) 2101.4300 / E-mail: rosaliaamanda641@gmail.com

SOUZA, Jéssica Mileny de Andrade. Graduanda em Licenciatura em Química.

Instituto Federal do Sertão Pernambucano - Campus Petrolina. Rua Maria Luiza de Araújo Gomes Cabral, S/N, João de Deus - Petrolina - Pernambuco - Brasil. CEP: 56.316-686 / Telefone: (87) 2101.4300 / E-mail: jessicaribeiro12370@gmail.com

LIMA, Yanka Micaelle Menezes. Graduanda em Licenciatura em Química.

Instituto Federal do Sertão Pernambucano - Campus Petrolina. Rua Maria Luiza de Araújo Gomes Cabral, S/N, João de Deus - Petrolina - Pernambuco - Brasil. CEP: 56.316-686 / Telefone: (87) 2101.4300 / E-mail: yankamicaelle71@gmail.com

VIEIRA, Maria do Socorro Tavares Cavalcante. Professora Pedagoga do IF-SERTÃO-PE Campus Petrolina, Mestre em Psicologia e doutoranda em Agroecologia e Desenvolvimento Territorial.

Instituto Federal do Sertão Pernambucano - Campus Petrolina. Rua Maria Luiza de Araújo Gomes Cabral, S/N, João de Deus - Petrolina - Pernambuco - Brasil. CEP: 56.316-686 / Telefone: (87) 2101.4300 / E-mail: socorro.tavares@ifsertao-pe.edu.br

LIMA JÚNIOR, Geraldo Vieira de Lima. Químico Industrial, Mestre e doutorando em Ciências dos Materiais.

Instituto Federal do Sertão Pernambucano - Campus Petrolina. Rua Maria Luiza de Araújo Gomes Cabral, S/N, João de Deus - Petrolina - Pernambuco - Brasil. CEP: 56.316-686 / Telefone: (87) 2101.4300 / E-mail: geraldo.vieira@ifsertao-pe.edu.br

ALENCAR, Fernanda Cavalcante de. Engenheira, Mestre e doutoranda em Ciências dos Materiais.

Universidade Federal do Vale do São Francisco - Campus Juazeiro. Av. Antônio Carlos Magalhães, 510, Country Club - Juazeiro - Bahia - Brasil. CEP: 48902-300 / Telefone: (74) 2102.7609 / E-mail: nandacvalencar@gmail.com

\section{RESUMO}

Este trabalho objetivou estudar o uso do óleo essencial de manjericão (Ocimum basilicum L.) na produção de sabonetes artesanais. Esta erva, pertencente à família Lamiaceae, é popularmente conhecida pelas propriedades medicinais associadas ao seu óleo essencial, substância utilizada no desenvolvimento de diferentes produtos. A fabricação dos sabonetes artesanais teve início com a colheita das folhas do manjericão, seguida da extração do óleo essencial, a partir da técnica de hidrodestilação, e da produção dos sabonetes. Para avaliar a aceitação do produto final pelos usuários, foi realizada uma análise sensorial para determinar a amostra com melhores atributos. Evidenciou-se que os métodos para extração do óleo essencial e para fabricação dos sabonetes artesanais cumpriram os objetivos determinados, possibilitando a obtenção de sabonetes com as características desejadas. Quanto à avaliação pelo público, a amostra A3, desenvolvida com 1,3 $\mathrm{mL}$ de óleo essencial, mostrou-se como a de maior aceitação.

Palavras-chave: Manjericão, óleo essencial, sabonete artesanal. 
GOMES, A. R. A.; SOUZA, J. M. A.; LIMA, Y. M. M.; VIEIRA, M. S. T. C.; LIMA JÚNIOR, G. V.; ALENCAR, F. C. Produção de sabonetes artesanais a partir do óleo essencial do manjericão (Ocimum basilicum L.)

\section{ABSTRACT}

This work aimed to study the use of basil essential oil (Ocimum basilicum L.) in handmade soaps production. This herb belongs to the Lamiaceae family and it is popularly known for the medicinal properties associated with its essential oil, substance used in the manufacture of different products. The manufacture of handmade soaps began harvesting basil leaves, followed the extraction of essential oil using the hydrodistillation technique and the soaps production. To assess the acceptance of the final product by users a sensory analysis was performed to determine the sample with best attributes. It became evident that the methods for extracting essential oil and for making handmade soaps fulfilled the objectives making it possible to obtain soaps with the desired characteristics. As for public evaluation sample A3 developed with $1.3 \mathrm{~mL}$ of essential oil proved to be the most widely accepted.

Keywords: Basil, essential oil, handmade soap.

\section{Introdução}

As ervas aromáticas são plantas classificadas como subarbustos, cujas folhas possuem aromas característicos e apresentam um potencial oleaginoso significativo para extração de óleos essenciais (PEREIRA; MOREIRA, 2011). Segundo Goulart (2015), tais ervas são comumente utilizadas como tempero para pratos diversos e como remédios caseiros. Na indústria, são empregadas frequentemente na aromatização de alimentos e bebidas; e na manipulação de remédios e cosméticos através do uso dos seus óleos essenciais.

Os óleos essenciais são misturas complexas, que podem conter diversos compostos orgânicos, desses, o que se apresenta em maior concentração é o que confere a atividade farmacológica da erva (FERREIRA, 2014). Diferentes técnicas podem ser utilizadas para extrair o óleo essencial de plantas, destacam-se: a extração por prensagem, maceração, extração com solventes voláteis, enfleurage e destilação por arraste a vapor. Esse último método se mostra como o mais eficiente e de menor custo entre os citados (GUIMARÃES; OLIVEIRA; ABREU, 2000).

Dentre as ervas aromáticas, destaca-se o manjericão (Ocimum basilicum L.), popularmente conhecido como alfavaca, manjericão branco e manjericão-doce, erva pertencente à família Lamiaceae (MORAIS, 2006) e oriunda do Sudoeste Asiático e da África Central (VELOSO et al, 2015). É uma planta popular em festas regionais na Europa e na Ásia, considerada sagrada por alguns povos hindus e vista como um símbolo de amor (TEIXEIRA, 2018).

No Brasil, assim como em outros países, o manjericão também é uma erva de uso comum. As folhas são utilizadas no preparo de refeições e na formulação de remédios caseiros para cólicas, vômitos, constipação, depressão e menopausa; também são empregadas na produção de xampus, sabonetes e perfumes, que apresentam propriedades fungicidas, cicatrizantes e repelentes (ROSADO et al., 2011). A maior concentração de cultivo encontra-se na região Nordeste, com cerca de 5 tipos de espécies distintas (PEREIRA; MOREIRA, 2011), dentre elas a Ocimum basilicum L., utilizada neste projeto.

O óleo essencial de manjericão é constituído majoritariamente de linalol, um monoterpeno alcoólico terciário acíclico de fórmula molecular $\left(\mathrm{C}_{10} \mathrm{H}_{18} \mathrm{O}\right)$. O linalol pode apresentar propriedades 
GOMES, A. R. A.; SOUZA, J. M. A.; LIMA, Y. M. M.; VIEIRA, M. S. T. C.; LIMA JÚNIOR, G. V.; ALENCAR, F. C. Produção de sabonetes artesanais a partir do óleo essencial do manjericão (Ocimum basilicum L.)

químicas e biológicas distintas devido a seus dois estereoisômeros: 3R-(-)-Linalol e 3S-(+)- Linalol. Dessa forma, a depender do estereoisômero em questão, o composto pode assumir um aroma de lavanda e flores frescas ou um aroma cítrico e herbáceo.

O óleo essencial do manjericão foi utilizado neste trabalho devido à presença significativa de linalol, que é normalmente utilizado como fixador de fragrâncias (CAMARGO; VASCONCELOS, 2014), conferindo aos sabonetes um aroma forte e duradouro; e para avaliar, futuramente, uma possível atividade farmacológica associada ao manjericão com o uso recorrente do óleo na forma de sabonetes artesanais.

O sabonete é um detergente sintético destinado à limpeza corporal e é conhecido como o produto de higiene mais antigo utilizado pelo homem (SOARES, 2014; apud, BONADEO, 2010; DRAELOS, 2009). O sabonete na sua forma pura (artesanal) é composto basicamente de glicerina, um composto orgânico de fórmula $\mathrm{C}_{3} \mathrm{H}_{8} \mathrm{O}_{3}$ que possui propriedades emolientes, lubrificantes, umectantes, hidratantes e higroscópicas, que contribuem para absorção da água na pele e nos cabelos, promovendo hidratação e maciez (CAETANO, 2020). Em contato com a pele, age como "um agente limpador extremamente suave, leve e hidratante" (BOSCHEINEN, 2014).

Boscheinen (2014) destaca outros benefícios dos sabonetes artesanais, tais como: possuem fragrâncias de óleos essenciais naturais, ao invés de fragrâncias sintéticas; são produzidos em pequenos lotes, o que thes confere maior frescor em relação aos sabonetes industrializados; os óleos essenciais utilizados possuem propriedades medicinais, que os tornam bons solventes para o corpo; e a espuma criada por esses sabonetes não causa danos ao meio ambiente, uma vez que são orgânicos e não possuem poluentes químicos.

Nesse contexto, os principais objetivos deste estudo foram: realizar a extração do óleo essencial das folhas do manjericão, através do método de hidrodestilação, e verificar a eficiência deste; confeccionar sabonetes artesanais utilizando o óleo extraído, para futuros estudos quanto ao potencial cicatrizante associado ao manjericão; e avaliar a aceitabilidade dos sabonetes em termos de fragrância.

\section{Material e Métodos}

Para este trabalho, foram utilizados, como fonte de dados para o embasamento teórico, artigos sobre o manjericão (Ocimum basilicum L.) e sobre a fabricação de sabonetes artesanais, coletados nas bibliotecas da Scielo, Periódicos Capes e Google Acadêmico. As buscas foram realizadas em abril de 2019, a partir das palavras-chave: manjericão, óleo essencial e sabonete artesanal.

Para a produção dos sabonetes, foi aplicada a metodologia experimental, que consiste em submeter os objetos de estudo à influência de certas variáveis, em condições controladas e conhecidas pelo investigador, intencionando observar os resultados produzidos no objeto (FREITAS E PRODANOV, 2013). 
GOMES, A. R. A.; SOUZA, J. M. A.; LIMA, Y. M. M.; VIEIRA, M. S. T. C.; LIMA JÚNIOR, G. V.; ALENCAR, F. C. Produção de sabonetes artesanais a partir do óleo essencial do manjericão (Ocimum basilicum L.)

A fabricação dos sabonetes ocorreu no laboratório de Bioquímica do IF-SERTÃO-PE, Campus Petrolina, e seguiu os passos apresentados na Figura 1.

Figura 1. Fluxograma das atividades realizadas

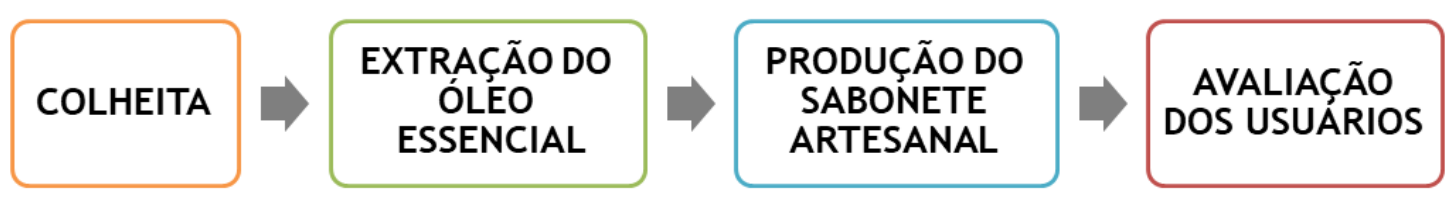

Fonte: Autores.

A colheita do manjericão ocorreu no Recanto Madre Paulina, localizado na Rua José Costa Lima, 326, Ouro Preto, Petrolina, Pernambuco, Brasil. O procedimento foi realizado no período da manhã, horário em que o óleo se apresenta na forma mais aromática devido à temperatura (SILVA, 2000).

A extração do óleo essencial foi realizada através da hidrodestilação, variante da técnica de destilação por arraste a vapor. Nesse método, o destilador é utilizado como uma única caldeira, onde ocorre a total imersão das folhas, que é aquecida de modo direto. Posteriormente ao aquecimento, é possível observar a evaporação dos compostos voláteis acompanhados do vapor de água. Após a evaporação, ocorre a condensação, etapa que permite a separação do óleo e da água devido à diferença de densidade desses compostos (FERREIRA, 2014). Nesse processo de extração, inicialmente, as folhas foram pesadas em uma balança e, em seguida, colocadas em um balão de fundo redondo de $3000 \mathrm{~mL}$ com água destilada até cobri-las, mantendo-as em aquecimento e com o balão acoplado ao clevenger ${ }^{1}$. Após o aquecimento, a água evaporou arrastando os componentes voláteis presentes na planta. Com a posterior condensação, a separação do óleo essencial da água foi possível devido à diferença de densidade. 0 óleo obtido foi extraído com uma pipeta de Pasteur ${ }^{2}$ e colocado em um eppendorf ${ }^{3}$.

A produção dos sabonetes artesanais de manjericão foi realizada por meio de dois processos físicos: a fusão, passagem da base glicerinada no estado sólido para o estado líquido; e a solidificação, passagem da base glicerinada e demais componentes do estado líquido para o estado sólido.

\footnotetext{
${ }^{1}$ Aparelho para destilação clevenger para determinação de óleos essências com balão. Utilizado na extração de óleos vegetais. 0 sistema de arraste por vapor d'água e/ou destilação a vapor é o método mais utilizado e viável economicamente para extração de óleos vegetais.

${ }^{2}$ A pipeta de Pasteur é um utensílio semelhante a um conta-gotas, geralmente formada por um tubo de vidro de ponta afilada. Serve para efetuar a transferência de pequenas porções de líquidos. Criada pelo químico francês Louis Pasteur, recebe este nome em sua homenagem.

${ }^{3}$ Tubo de microcentrífuga, é um pequeno tubo de plástico com formato cilíndrico e fundo cônico, com tampa acoplada.
} 
GOMES, A. R. A.; SOUZA, J. M. A.; LIMA, Y. M. M.; VIEIRA, M. S. T. C.; LIMA JÚNIOR, G. V.; ALENCAR, F. C. Produção de sabonetes artesanais a partir do óleo essencial do manjericão (Ocimum basilicum L.)

Nesse processo, foram utilizados o corante artificial (de coloração verde); a essência, neste caso o óleo essencial extraído; as sementes do manjericão; e a base glicerinada (massa transparente constituída basicamente de óleos e gorduras, solventes e solução de soda) (MERCADANTE; ASSUMPÇÃO, 2010).

Inicialmente, a base glicerinada foi cortada e pesada, para posteriormente ser aquecida com auxílio de uma chapa aquecedora. Em seguida, com a base já em estado líquido, acrescentouse o óleo essencial extraído, o corante e as sementes retiradas do manjericão (para reafirmar o caráter natural do sabonete e conferir textura). Após a homogeneização desses materiais com a assistência de um bastão de vidro, o conteúdo final foi disposto em formas de silicone. Após a completa solidificação, os sabonetes foram desenformados e reservados em recipientes fechados.

$\mathrm{Na}$ etapa de avaliação pelos usuários, o objetivo foi determinar um aroma considerado agradável, para isso, utilizou-se a análise sensorial, técnica que utiliza os sentidos humanos para avaliar as características ou atributos de um produto (CERQUEIRA, 2015). 0 teste realizado consistiu em avaliar três amostras de sabonete e organizá-las de modo crescente em relação à fragrância mais aceitável (teste de ordenação). Foram selecionados 15 alunos do curso Licenciatura em Química do IF-SERTÃO-PE Campus Petrolina, de forma aleatória e voluntária, para participar do experimento com o intuito de identificar a amostra de sabonete que possuísse o aroma mais agradável para o uso (Figura 2).

Figura 2. Questionário aplicado para avaliação pelos participantes

\begin{tabular}{lll|}
\hline Amostra: Sabonete & Julgador: Data: \\
Você está recebendo três amostras codificadas. Avalie cada uma, \\
colocando-as em ordem crescente de sua preferência da fragrância. \\
\\
PRIMEIRA & SEGUNDA & TERCEIRA \\
\hline
\end{tabular}

Fonte: Autores.

\section{Resultados e discussão}

As colheitas dos caules foram realizadas em três dias distintos, todas no período da manhã entre os horários de $7 \mathrm{~h}$ e $8 \mathrm{~h}$. Durante essa etapa, observou-se que o aroma das folhas dos exemplares de manjericão avaliados (Figura 3) era cítrico e herbáceo, indicando que o monoterpeno linalol presente na variedade estudada possui configuração dextrorrotatória [(+)-Linalol], sugerindo a presença do isômero coriandrol (CAMARGO; VASCONCELOS, 2014).

Depois de colhidos, os caules foram levados ao laboratório de Bioquímica do IF-SERTÃO-PE, Campus Petrolina, e as folhas foram removidas, lavadas com água destilada, avaliadas quanto à 
GOMES, A. R. A.; SOUZA, J. M. A.; LIMA, Y. M. M.; VIEIRA, M. S. T. C.; LIMA JÚNIOR, G. V.; ALENCAR, F. C. Produção de sabonetes artesanais a partir do óleo essencial do manjericão (Ocimum basilicum L.)

presença de larvas (que poderiam interferir no processo, prejudicando a extração) e conservadas em ambiente climatizado.

Figura 3. Exemplar de manjericão (Ocimum basilicum L.) utilizado para colheita

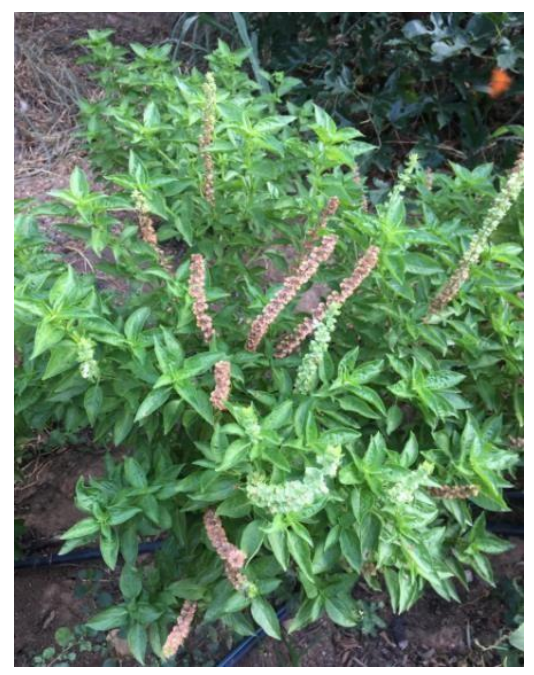

Fonte: Autores.

Para a realização das extrações de óleo essencial, montou-se um sistema fechado para a hidrodestilação, composto por destilador, balão volumétrico, clevenger e bomba de vácuo (Figura 4).

Figura 4. Sistema fechado para extração do óleo essencial

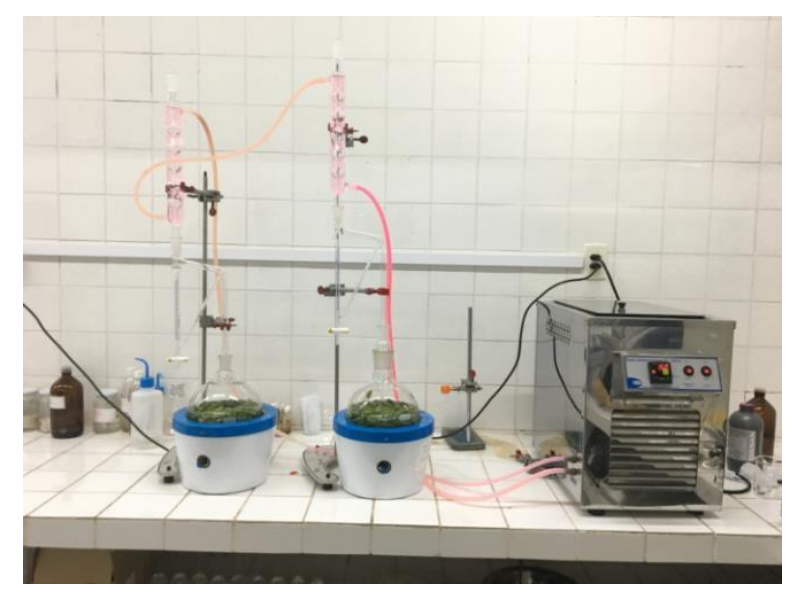

Fonte: Autores.

Foram realizadas 7 extrações (Tabela 1), com o intuito de quantificar o volume de óleo essencial que seria obtido para a quantidade de folhas utilizadas no processo.

Verificou-se que as folhas passaram a murchar (indícios de desidratação) depois de colhidas, o que é comum para a maioria das plantas depois de removidas do solo. Dessa forma, as extrações de óleo essencial foram realizadas no período da manhã, após os procedimentos de colheita, 
GOMES, A. R. A.; SOUZA, J. M. A.; LIMA, Y. M. M.; VIEIRA, M. S. T. C.; LIMA JÚNIOR, G. V.; ALENCAR, F. C. Produção de sabonetes artesanais a partir do óleo essencial do manjericão (Ocimum basilicum L.)

lavagem e avaliação. Por limitações de uso do sistema de hidrodestilação e para avaliar o rendimento da extração após várias horas da colheita, a amostra 7 foi executada à noite.

Tabela 1. Resultados obtidos da extração de óleo essencial do manjericão

\begin{tabular}{cccccc}
\hline Amostra & $\begin{array}{c}\text { Data da } \\
\text { colheita }\end{array}$ & $\begin{array}{c}\text { Massa das } \\
\text { folhas }(\mathbf{g})\end{array}$ & $\begin{array}{c}\text { Início da } \\
\text { extração }\end{array}$ & $\begin{array}{c}\text { Fim da } \\
\text { extração }\end{array}$ & $\begin{array}{c}\text { Óleo essencial } \\
(\mathrm{mL})\end{array}$ \\
\hline 1 & $23 / 04 / 19$ & 204 & $9 \mathrm{~h} 20$ & $16 \mathrm{~h} 23$ & 0,8 \\
\hline 2 & $23 / 04 / 19$ & 235 & $9 \mathrm{~h} 20$ & $16 \mathrm{~h} 23$ & 0,2 \\
\hline 3 & $25 / 04 / 19$ & 200 & $10 \mathrm{~h} 55$ & $13 \mathrm{~h} 00$ & 0,4 \\
\hline 4 & $25 / 04 / 19$ & 191 & $10 \mathrm{~h} 55$ & $13 \mathrm{~h} 00$ & 0,7 \\
\hline 5 & $29 / 05 / 19$ & 206 & $11 \mathrm{~h} 31$ & $13 \mathrm{~h} 30$ & 0,2 \\
\hline 6 & $29 / 05 / 19$ & 207 & $11 \mathrm{~h} 31$ & $13 \mathrm{~h} 30$ & 0,6 \\
\hline 7 & $29 / 05 / 19$ & 206 & $18 \mathrm{~h} 28$ & $20 \mathrm{~h} 30$ & 0,5 \\
\hline
\end{tabular}

Fonte: Autores.

Com relação ao tempo de extração, Veloso et al. (2015) sugere que cerca de $2 \mathrm{~h}$ são suficientes para obtenção do óleo essencial. No entanto, para observar em que ponto cessava, de fato, a obtenção do óleo, os primeiros experimentos foram realizados como testes. Por essa razão, o tempo de extração das amostras 1 e 2 foi maior, cerca de $7 \mathrm{~h}$.

Com base nos testes iniciais, que demonstraram que o óleo essencial pode ser completamente obtido em até $3 \mathrm{~h}$ de duração do experimento, optou-se por diminuir o tempo das extrações seguintes para períodos entre $2 \mathrm{~h}$ e $3 \mathrm{~h}$.

É possível observar na Tabela 1 que os volumes de óleo essencial obtidos variaram em torno de uma média de $0,5 \mathrm{~mL}$. Na amostra 2, por exemplo, foram utilizados $235 \mathrm{~g}$ de folhas e o volume obtido foi $0,2 \mathrm{~mL}$, enquanto que na amostra 4 , em que $191 \mathrm{~g}$ de folhas foram utilizadas, obteve-se $0,7 \mathrm{~mL}$.

Ferreira (2014) afirma que tal variação na obtenção do óleo essencial pode ser explicada por fatores internos e externos à planta, classificados como: intrínsecos, que dependem da genética e fisiologia da planta; ou extrínsecos, que correspondem às condições ambientais e de colheita. Esses fatores podem ser listados especificamente como:

a. Idade da planta aromática: fator que afeta a composição dos óleos essenciais produzidos;

b. Meses de colheita e altura do dia: os óleos essenciais produzidos variam em quantidade durante o ano e, para determinadas espécies, variam também durante o dia (com destaque para um maior volume nas primeiras horas da manhã); 
GOMES, A. R. A.; SOUZA, J. M. A.; LIMA, Y. M. M.; VIEIRA, M. S. T. C.; LIMA JÚNIOR, G. V.; ALENCAR, F. C. Produção de sabonetes artesanais a partir do óleo essencial do manjericão (Ocimum basilicum L.)

c. Radiação solar: o sol tem uma grande influência no crescimento e metabolismo das plantas aromáticas e, consequentemente, na produção de óleos essenciais. Geralmente, as plantas aromáticas requerem grandes quantidades de luz solar;

d. Temperatura: é um fator que interfere na composição dos óleos essenciais e, consequentemente, no rendimento de extração do óleo;

e. Tratamento pós-colheita do material vegetal: existem vários parâmetros para considerar, o tipo de transporte, local de armazenamento, tipo de secagem e limpeza, por exemplo, são fatores que precisam ser avaliados para que qualquer tipo de degradação ou perda seja evitada. 0 transporte violento, por exemplo, pode ocasionar danos nas células secretoras e de armazenamento e este composto pode ficar exposto à oxidação, diminuindo o rendimento da extração do óleo essencial.

Após a execução dos experimentos e com o término de todas as extrações, os volumes de óleo obtido foram retirados do clevenger e reservados em tubos do tipo eppendorf (Figura 5).

Figura 5. Óleo essencial extraído

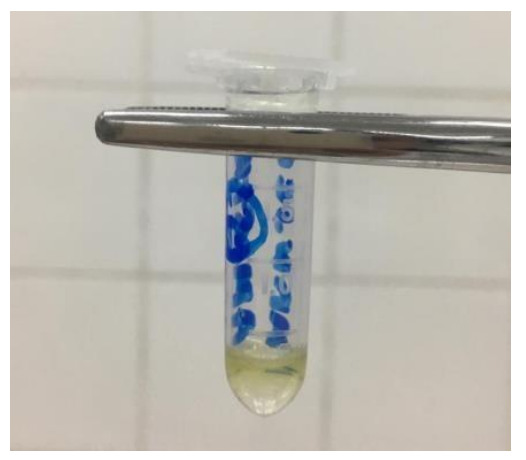

Fonte: Autores.

Foram produzidas três amostras do produto final com diferentes quantidades do óleo essencial extraído. Em cada amostra de sabonete, A1, A2 e A3, foram depositados, respectivamente, 0,2 mL, 1,1 mL e 1,3 $\mathrm{mL}$ de óleo essencial (Tabela 2). Foram confeccionadas seis repetições de cada amostra, totalizando 18 sabonetes de $15 \mathrm{~g}$, moldados em formas de silicone no formato de folhas (Figura 6).

Tabela 2. Diferentes amostras de sabonetes produzidas

\begin{tabular}{cccc}
\hline Amostra & $\begin{array}{c}\text { Base } \\
\text { glicerinada }(\mathbf{g})\end{array}$ & $\begin{array}{c}\text { Volume de } \\
\text { óleo }(\mathrm{mL})\end{array}$ & $\begin{array}{c}\text { Quantidade de } \\
\text { amostras (Unidade) }\end{array}$ \\
\hline 1 & 138 & 0,2 & 6 \\
2 & 140 & 1,1 & 6 \\
3 & 156 & 1,3 & 6 \\
\hline
\end{tabular}

Fonte: Autores. 
GOMES, A. R. A.; SOUZA, J. M. A.; LIMA, Y. M. M.; VIEIRA, M. S. T. C.; LIMA JÚNIOR, G. V.; ALENCAR, F. C. Produção de sabonetes artesanais a partir do óleo essencial do manjericão (Ocimum basilicum L.)

Figura 6. (a) Forma utilizada para moldar os sabonetes e (b) sabonetes prontos pós solidificação

(a)

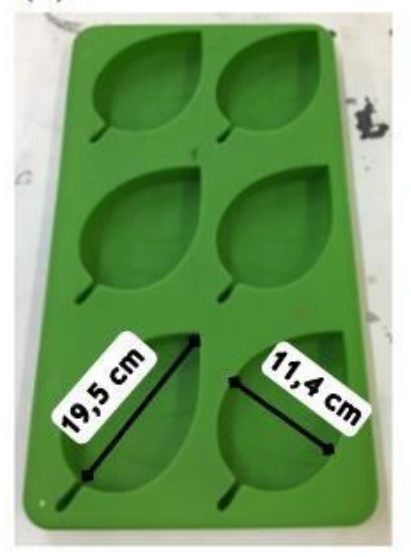

(b)

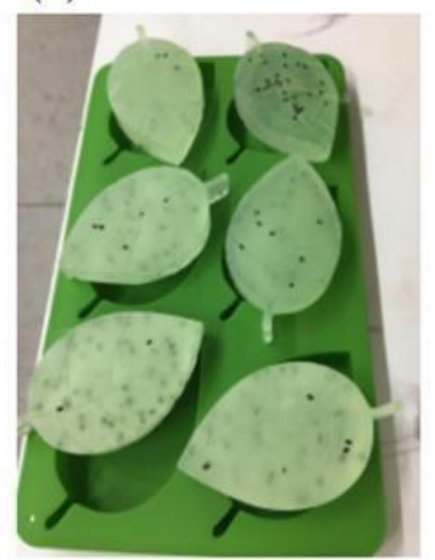

Fonte: Autores.

Após o processo de solidificação, em temperatura ambiente, foi possível constatar que os sabonetes apresentavam a textura e a consistência desejáveis.

$\mathrm{Na}$ fase de avaliação pelos usuários, foi verificada a aceitação da intensidade da fragrância no sabonete artesanal. O objetivo foi determinar um aroma considerado agradável, para isso, utilizou-se a análise sensorial. O teste de ordenação consistiu em avaliar as três amostras de sabonete (A1, A2 e A3) e organizá-las de modo crescente em relação à fragrância mais agradável (Tabela 3).

Tabela 3. Avaliação das amostras em termos de fragrância

\begin{tabular}{llcc}
\hline \multicolumn{3}{l}{ Amostras: Sabonetes artesanais fabricados a partir do óleo essencial do manjericão } \\
\hline Julgador & Ordem crescente de preferência em termos de & fragrância \\
\hline 1 & $\mathrm{~A} 1$ & $\mathrm{~A} 2$ & $\mathrm{~A} 3$ \\
2 & $\mathrm{~A} 1$ & $\mathrm{~A} 2$ & $\mathrm{~A} 3$ \\
3 & $\mathrm{~A} 1$ & $\mathrm{~A} 2$ & $\mathrm{~A} 3$ \\
4 & $\mathrm{~A} 1$ & $\mathrm{~A} 3$ & $\mathrm{~A} 2$ \\
$\mathbf{5}$ & $\mathrm{A} 1$ & $\mathrm{~A} 2$ & $\mathrm{~A} 3$ \\
6 & $\mathrm{~A} 1$ & $\mathrm{~A} 3$ & $\mathrm{~A} 2$ \\
$\mathbf{7}$ & $\mathrm{A} 1$ & $\mathrm{~A} 2$ & $\mathrm{~A} 3$ \\
8 & $\mathrm{~A} 1$ & $\mathrm{~A} 2$ & $\mathrm{~A} 3$ \\
9 & $\mathrm{~A} 1$ & $\mathrm{~A} 2$ & $\mathrm{~A} 3$ \\
10 & $\mathrm{~A} 1$ & $\mathrm{~A} 2$ & $\mathrm{~A} 3$ \\
11 & $\mathrm{~A} 1$ & $\mathrm{~A} 2$ & $\mathrm{~A} 3$ \\
12 & $\mathrm{~A} 1$ & $\mathrm{~A} 3$ & $\mathrm{~A} 2$ \\
13 & $\mathrm{~A} 1$ & $\mathrm{~A} 2$ & $\mathrm{~A} 3$ \\
14 & $\mathrm{~A} 1$ & $\mathrm{~A} 3$ & $\mathrm{~A} 2$ \\
15 & $\mathrm{~A} 1$ & $\mathrm{~A} 2$ & $\mathrm{~A} 3$ \\
$\mathrm{~N}^{\circ}$ total de amostras avaliadas por cada participante: & 3 & \\
\hline
\end{tabular}

Fonte: Autores. 
GOMES, A. R. A.; SOUZA, J. M. A.; LIMA, Y. M. M.; VIEIRA, M. S. T. C.; LIMA JÚNIOR, G. V.; ALENCAR, F. C. Produção de sabonetes artesanais a partir do óleo essencial do manjericão (Ocimum basilicum L.)

De acordo com a Tabela 3, a amostra de sabonete que obteve o melhor resultado em termos de fragrância foi a $A 3$, seguida da $A 2$ e da $A 1$. Esse resultado demonstra que os participantes preferiram a amostra com o maior volume de óleo essencial utilizado, que apresentava a fragrância mais intensa dentre os sabonetes produzidos.

\section{Conclusões}

A partir dos resultados obtidos, foi possível constatar que os métodos utilizados para a obtenção do óleo essencial e para a fabricação de sabonetes artesanais se mostraram eficientes e permitiram a obtenção de sabonetes com as características desejadas.

É importante ressaltar que a vivência deste projeto proporcionou o acesso das graduandas à pesquisa científica, possibilitando o estudo de técnicas laboratoriais e o manuseio de equipamentos, contribuindo significativamente para o desenvolvimento profissional e para a construção de um senso crítico; e que o IF-SERTÃO-PE, como instituição comprometida, assegurou o desenvolvimento desse estudo sem maiores limitações.

Espera-se que este trabalho inspire outros estudos a cerca do emprego de ervas aromáticas em produtos saneantes, principalmente quanto às possíveis propriedades medicinais associadas a tais plantas. 0 próximo passo deste trabalho, uma vez que foi comprovada a eficiência da produção em laboratório, é estudar a ação cicatrizante e antisséptica desses sabonetes artesanais fundamentos no óleo essencial do manjericão.

\section{Referências}

BOSCHEINEN, K. Criar e arte. Os tipos e os benefícios dos sabonetes naturais. Disponível em: <http://criareartepresentes.blogspot.com/2014/12/os-tipos-e-beneficios-dos-sabonetes.html>. Acesso julho de 2019.

CAETANO, B. Glicerina: o que é, benefícios e como usar?. Minha Vida, 2020. Disponível em:<https://www.minhavida.com.br/beleza/tudo-sobre/33653-glicerina>. Acesso em agosto de 2020.

CAMARGO, S. B.; DE VASCONCELOS, D. F. S. A. Atividades biológicas de Linalol: conceitos atuais e possibilidades futuras deste monoterpeno. Revista de Ciências Médicas e Biológicas, v. 13, n. 3, p. 381-387, 2014.

CERQUEIRA, R. Análise sensorial em aromas e fragrâncias. 2015. 68slides. Disponível em: <https://www.crq4.org.br/sms/files/file/mini_sensorial_2015_site.pdf Acesso em julho de 2019.

FERREIRA, A. R. A. Uso de óleos essenciais como agentes terapêuticos. 2014. 87f. Dissertação (Mestrado em Ciências Farmacêuticas) - Faculdade de ciências de saúde, Universidade Fernando Pessoa, Porto.

GOULART, V. M. Efeito da hipergravidade simulada sobre a germinação, o crescimento e a produção de óleo essencial de manjericão (Ocimum basilicum L.). 2015. 56f. Dissertação (Mestrado em Biotecnologia Farmacêutica) - Faculdade de Farmácia, Universidade Católica do Rio Grande do Sul, Porto Alegre. 
GOMES, A. R. A.; SOUZA, J. M. A.; LIMA, Y. M. M.; VIEIRA, M. S. T. C.; LIMA JÚNIOR, G. V.; ALENCAR, F. C. Produção de sabonetes artesanais a partir do óleo essencial do manjericão (Ocimum basilicum L.)

GUIMARÃES, P. I. C.; OLIVEIRA, R. E. C.; DE ABREU, R. G. Extraindo óleos essenciais de plantas. Química Nova na Escola. $n^{\circ}$ 11, p. 45-46, 2000.

LUPE, F. A. et al. Estudo da composição química de óleos essenciais de plantas aromáticas da Amazônia. 2007.

MERCADANTE, R.; ASSUMPÇÃO, L. Massa base para sabonetes: Fabricando sabonetes sólidos. Projeto Gerar, v. 9, p. 16, 2010.

MORAIS, T. P. S. Produção e composição do óleo essencial de manjericão (Ocimum basilicum L.) sob doses de cama de frango. 2006.50f.Dissertação (mestrado em agronomia) - Instituto de ciências agrárias, Universidade Federal de Uberlândia, Minas Gerais.

ORMEÑO, E.; FERNÁNDEZ, C. Los terpenos de las plantas. Investigación y ciencia, v. 428, n. 1, p. 62-69, 2012.

PEREIRA, R.; MOREIRA, A. L. M. Manjericão: cultivo e utilização. Embrapa Agroindústria TropicalDocumentos (INFOTECA-E), 2011.

PRODANOV, C. C.; FREITAS, E. C. Metodologia do trabalho científico: métodos e técnicas da pesquisa e do trabalho acadêmico. 2a Edição. Editora Feevale, 2013.

ROSADO, L. D. S. et al. Influência do processamento da folha e tipo de secagem no teor e composição química do óleo essencial de manjericão cv. Maria Bonita. Ciência e agrotecnologia, v. 35, n. 2, p. 291-296, 2011.

SILVA, F. Óleo essencial e conservação pós-colheita de manjericão (Ocimum basilicum L.) em dois horários e duas épocas de colheita. 2000. 92f. Tese (Doutorado em Fitotecnia) - Universidade Federal de Viçosa, Minas Gerais.

SOARES, Nayana Ribeiro. Avaliação da atividade antimicrobiana e caracterização físico-química de sabonete líquido à base de óleo de baru, buriti e pequi. 2013. 70f. Dissertação (Mestrado em Ciência e Tecnologia de Alimentos) - Faculdade de Agronomia, Universidade Federal de Goiás, Goiânia.

TEIXEIRA, M. Manjericão - sagrado e símbolo do amor e da coragem. Folha de Pernambuco, Pernambuco, 02 de Maio de 2018. Disponível em:

<https://www.folhape.com.br/cultura/manjericao-sagrado-e-simbolo-do-amor-e-dacoragem/67107/>. Acesso em agosto de 2020.

VELOSO, R. A. et al. Óleos essenciais de manjericão e capim citronela no controle de larvas de Aedes aegypti. Revista Verde de Agroecologia e Desenvolvimento Sustentável, 2015.

VITTI, A. M. S.; BRITO, J. O. Óleo essencial de eucalipto. Documentos florestais, v. 17, p. 1, 2003. 